\title{
Quantities and units in clinical chemistry
}

\author{
R. DYBKÆR \\ From the Commission on Quantities and Units in Clinical Chemistry (of IUPAC) \\ and the International Federation for Clinical Chemistry
}

The Commission on Clinical Chemistry (CCC) of the International Union of Pure and Applied Chemistry (IUPAC) in 1965 nominated a Subcommission for Standards and Units in Clinical Chemistry. ${ }^{1}$ Concerning units, the primary task of the subcommission was to study (1) the individual and national efforts to counteract the increasingly chaotic use of quantities and units in clinical chemistry; (2) the current usage in related fields of science, especially biochemistry and general chemistry; and (3) the official recommendations from IUPAC, the International Union of Biochemistry (IUB), the International Union of Pure and Applied Physics (IUPAP), and the International Organization for Standardization (ISO). Secondarily, the subcommission was to submit a draft for a CCC recommendation.

An intermediate result, the pamphlet $A$ Primer of Quantities and Units in Clinical Chemistry (Dybkær and Jørgensen, 1966), was distributed among a number of national clinical chemical societies ${ }^{2}$ (all the members of the International Federation for Clinical Chemistry (İFCC)) and criticism was invited. At the Sixth International Congress of Clinical Chemistry in Munich, 1966, the contents were approved, with minor modifications, by CCC and IFCC.

The preparation of a draft for the Recommendation 1966 of CCC and IFCC was left to R. Dybkær and K. Jørgensen. The result was approved by the titular members of $\mathrm{CCC}^{3}$ and forms part of the recently published, more comprehensive treatise Quantities and Units in Clinical Chemistry (Dybkær and Jørgensen, 1967). The Recom-

1J. E. Courtois, president (Paris), R. Dybkær and P. Lous (Copenhagen), N. F. Maclagan (London), M. Rubin (Washington, D.C.), and M. C. Sanz (Geneva).

'Australia, Belgium, Canada, Czechoslovakia, Denmark, Federal Republic of Germany, Finland, France, Iran, Japan, Netherlands, Norway. Sweden, Switzerland, UK, USA, and USSR.

'J. E. Courtois, president (France), J. de Wael (Netherlands), S. H. Jackson (Canada), A. L. Latner for N. F. Maclagan (UK), V. N. Orekhovitch (USSR), M. Rubin (USA), R. Ruyssen (Belgium), and M. C. Sanz, secretary (Switzerland).

Comments may be addressed to: R. Dybkær, MD, University Institute of Medical Microbiology, 22 Juliane Mariesvej, DK 2100, Copenhagen $\varnothing$, Denmark. mendation 1966 was finally accepted by the IUPAC Section on Clinical Chemistry in Prague 1967, and the future development was entrusted to the newly created Commission on Quantities and Units in Clinical Chemistry (CQUCC). ${ }^{4}$

RECOMMENDATION 1966 OF THE COMMISSION ON CLINICAL CHEMISTRY AND THE INTERNATIONAL FEDERATION FOR CLINICAL CHEMISTRY

The Recommendation 1966 consists of a systematic and thorough discussion of the basic and derived kinds of quantities and their appropriate units of main interest to the clinical chemist, especially for his communication with the clinicians. The foundation is the recommendations from IUPAC, IUB, IUPAP, and ISO.

While the monograph (Dybkær and Jørgensen, 1967) should be consulted for an appreciation of the background, principles, and details of the Recommendation 1966, two points merit special mention. First, it is recommended, as far as possible, to use the 'chemical' basic kind of quantity 'amount of substance' with its basic unit 'mole' (symbolized mol) instead of 'mass' and mass units. (The concept 'equivalent' as a unit is ambiguous and unnecessary.) Secondly, the 'litre' (or 'liter'; symbolized 'l') as redefined internationally (in 1964) is retained also in clinical chemistry as the fundamental unit of volume. (One litre is equal to one cubic decimetre exactly. ${ }^{5}$ The coherent unit in the Système Internationale d'Unités is 'cubic metre'.) The application of these two principles entails that derived kinds of quantities employing 'amount of substance' instead of 'mass' are preferred, eg 'molar concentration' in 'mole per litre' for 'mass concentration' (in 'kilogramme per litre').

The preferred factor symbols for units are powers of 10 having whole number exponents which are simple multiples of three: the internationally approved list now ranges from $10^{12}$ (tera-, T) to

'B. H. Armbrecht (Beltsville, Maryland, USA), R. Dybkær, president (Copenhagen), K. Jørgensen (Copenhagen), P. Métais (Strasbourg). ${ }^{8}$ Conférence Générale des Poids et Mésures, 1964. 
$10^{-18}$ (atto-, a). Consequently, 'decilitre' $\left(=10^{-1} 1=\right.$ $100 \mathrm{ml}$ ) is not recommended. In derived units only the numerator should contain a factor symbol; thus, $\mathrm{mmol} / 1, \mu \mathrm{mol} / 1$, etc are preferred for $\mu \mathrm{mol} / \mathrm{ml}$, $\mathrm{nmol} / \mathrm{ml}$ respectively, and the use of, $e g, \mathrm{mg} / 1 \mathrm{CO} \mathrm{ml}$ and $\mathrm{mol} / 100 \mathrm{ml}$ is discouraged.

With regard to quantity names the Recommendation 1966 states the principle that they should be unambiguous and, at least in print, should include three segments of information: the kind of system investigated, the component of special interest in this system (with a 'formula unit' appended if doubt might arise), and the kind of quantity employed; this is followed by the product of the numerical value and an appropriate recommended unit.

\section{SUPPLEMENTARY INFORMATION}

Apart from the Recommendation 1966 the monograph contains historical and chemical background information, proposals for future recommendations on kinds of quantities with appropriate units, and suggestions for the construction of systematic quantity names in clinical chemistry.

The Commission on Quantities and Units in Clinical Chemistry and IFCC do not, at present, make recommendations on the specific form of the names or abbreviations employed. They may vary with language and local requirements. Application of the naming principle given in the Recommendation 1966 may lead to systematic forms such as, eg: Serum-Acid phosphatase, enzyme concentration (Jacobsson, 1960) = 3.9 U/1; Serum-Albumin, mass concentration $=52 \mathrm{~g} / 1 ; 24$-hours-Urine-Calcium ion (Ca), amount of substance $=4.3 \mathrm{mmol}$; BloodHemoglobin $(\mathrm{Fe})$, molar concentration $=8.9 \mathrm{mmol} / \mathrm{l}$; Patient-Plasma, volume $=2.91$; and Plasma-
Platelets, particle concentration $=300 \times 10^{9}$ 居 The use of appropriate abbreviations for kind of system and kind of quantity appreciably shorten the length of the systematic names as shown in a list of examples; the longest of the above names $e g$, may be abbreviated to dU-Calcium ion(Ca) ams. The list also contains factors for conversio between some commonly used, but less satisfactory, expressions of quantities and those recommended.

\section{CONCLUSION}

The aim of the Recommendation 1966 is (1) reduce the number of usages for presentation of clinical chemical data and (2) to close the existing gap between the nomenclature in clinical chemistryb and that of allied fields of science.

The Commission on Quantities and Units if Clinical Chemistry and IFCC share the hope that the joint Recommendation 1966, which is in agrees ment with those of other pertinent internation bodies, will meet with approval in principle, and eventually lead to an international and consisterog nomenclature and use of quantity names and units in clinical chemistry. This, ultimately, should benefor the scientific worker as well as, and most importan the patient undergoing diagnosis and treatmen because misunderstandings will be fewer.

\section{REFERENCES}

Dybkær, R., and Jørgensen, K. (1966). A primer of quantities and units in clinical chemistry. Made on behalf of the Subcommitte for Standardization of Units in Clinical Chemistry of IFCE. Copenhagen.

-,- (1967). Quantities and Units in Clinical Chemistry. Includiff Recommendation 1966 of the Commission on Clinical Chemisty of the International Union of Pure and Applied Chemistry an of the International Federation for Clinical Chemistry. Munks. gaard, Copenhagen. 